\title{
Editorial
}

\section{The Experimenting Society}

\author{
Melinda F. Davis \\ University of Arizona
}

Donald Campbell wrote eloquently about the need to evaluate social reforms and lamented the lack of solid evaluation research to guide these reforms (1973). He suggested that social reforms be thought of as experiments, and society's focus be on important problems rather than single solutions to these problems. Campbell's vision of an experimenting society, in which reforms are evaluated and new approaches to social problems are developed based on evaluation outcomes has yet to be realized.

The need for rigorous evaluations of social reforms, combined with the lack of evaluation utilization are continuing problems without easy solutions. Some reforms, such as deinstitutionalization for individuals with mental illnesses and cognitive impairments, have taken place across decades, and the continuation of this process has not been guided by evaluation results. Evaluation, if not done well, can lead to spurious results and poor decisions. Further evaluation is a process that needs to be entered into with a questioning mind and self-correcting, at least in the long run, methodology.

Research requires considerable time and energy. Why, as evaluators, would we want to invest precious time and resources to examine the results of longstanding social programs or the effects of long-past events? The time-dependent records that would assist evaluation will not be available permanently. First, states and other organizations do not retain records forever. Records (such as the descriptions of programs, curricula, and participant data) may be kept for only a few years. Second, many individuals who lived through the New Deal and the Great Society are still here. In another 50 years, there will be nothing left but traces, usable only by historians.

If a social reform is important enough to study, how should we address it? Campbell recommended the use of multiple methods, and strongly encouraged the use of ethnographic data along with more quantitative indicators to evaluate programs (1994). At this point, clients, providers, and family members can be interviewed, even for programs that date back many years. It may be possible to use strong case study methodology, such as the random selection of cases, thick descriptions, and the 


\section{THE EXPERIMENTING SOCIETY}

incorporation of information from multiple sources (Sechrest, Stewart, Stickle, \& Sidani, 1996).

Deinstitutionalization for individuals with mental illnesses and cognitive impairments is one of many social reforms that has not been carefully evaluated. The published empirical literature is thin, including some small longitudinal evaluations (see Kunitoh, 2013), a few interesting ethnographic studies (e.g., Fido, \& Potts, 1989), and some analyses of national data (Raphael and Stoll, 2013). There is still time to conduct evaluation research on this topic. Whether it is worth the effort will be up to evaluators and funding agencies. "The job of the methodologist for the experimenting society is not to say what is to be done, but rather to say what has been done" (Campbell, 1973).

\section{References}

Campbell, D. T. (1973). Reforms as experiments. American Psychologist 24, 409-429.

Campbell, D. T. (1994). Retrospective and prospective on program impact assessment. Evaluation Practice, 15, 291-298.

Fido, R., \& Potts, M. (1989) 'It's not true what was written down!: Experiences of life in a mental handicap institution', Oral History, 17, 31-49.

Kunitoh, N. (2013). From hospital to the community: The influence of deinstitutionalization on discharged long-stay psychiatric patients. Psychiatry and Clinical Neurosciences, 67, 384-396.

Raphael, S., \& Stoll, M. A. (2013). Assessing the contribution of the deinstitutionalization of the mentally ill to growth in the US incarceration rate. The Journal of Legal Studies, 42, 187-222.

Sechrest, L. B., Stewart, M., Stickle, T, R., Sidani, S. (1996). Effective and Persuasive Case Studies. The Evaluation Center@HSRI, Center for Mental Health Services. 